J. Asiat. Soc. Bangladesh, Sci. 39(2): 239-246, December 2013

\title{
OCCURRENCE OF INTESTINAL PARASITES AMONG THE TEACHERS, STUDENTS AND STAFFS OF DHAKA UNIVERSITY
}

\author{
HAMIDA KHANUM ${ }^{1}$, FARZANA RAHMAN AND RIMI FARHANA ZAMAN \\ Parasitology Branch, Department of Zoology, University of Dhaka, Dhaka 1000
}

\begin{abstract}
The present study was conducted to find out the incidence of the intestinal parasites and their prevalence among the teachers, students and staffs of University of Dhaka, Bangladesh. The study revealed that the prevalence of intestinal protozoa and helminth parasites are common among the outdoor patients of University of Dhaka. A total of 350 stool samples was examined in the Pathology department of Medical Center of University of Dhaka from June 2009 to May 2010, four species of intestinal parasites were identified of which two species were protozoa (Entamoeba histolytica and Giardia intestinalis) and two species were nematodes (Ascaris lumbricoides and Trichuris trichiura). The overall prevalence of infestation was $23.14 \%$ where Entamoeba histolytica, Giardia intestinalis, Ascaris lumbricoides and Trichuris trichiura were found as $4.86 \%, 3.71 \%, 11.14 \%$ and $3.43 \%$ respectively. Highest prevalence was recorded in Ascaris lumbricoides (11.14\%) and the seasonal pattern showed that highest $(30 \%)$ prevalence occurred in rainy season and lowest $(17.19 \%)$ in winter season. The prevalence of intestinal parasites was higher in female $(30.56 \%)$ than in male $(22.29 \%)$.
\end{abstract}

Key words: Intestinal parasites, Teachers, Students, Staffs, Dhaka University

\section{Introduction}

Intestinal parasitic diseases are considered as a worldwide problem including Bangladesh. They have a detrimental effect on the health of millions of people every year. The prevalence of intestinal parasite in Bangladesh is quite high where infestation with protozoa and helminth parasites such as Giardia intestinalis, Entamoeba histolytica, Ascaris lumbricoides and Trichuris trichiura are major public health concern both in rural and urban areas (Saha and Chowdhury 1961, Muazzem and Ali 1968, Muttalib 1975, Muttalib et al. 1976, Islam et.al. 1975, Chowdhury 1978, Stoll et al. (1982), Khanum et al. (1999 and 2001). The first five year plan of Bangladesh (1973-1978) reported that $64 \%$ of the children of the country suffered from intestinal parasitic infection. Khanum et al. (1999 and 2005) worked on infestation of three intestinal worms in 600 children of different socio-economic status residing in three selected rural areas. They reported single and multiple infections by a number of parasites including A. lumbricoides, T. trichiura and hookworms. The prevalence was higher among the children who used pond water for drinking and washing utensils, open field

\footnotetext{
${ }^{1}$ Corresponding author: Email: hamida_khanum@yahoo.com
} 
for defecation, used clay after defecation and lived in mud and straw houses.

The World Health Organization (WHO) estimated that there were around 1000 million cases of ascariasis due to Ascaris lumbricoides, and 500 million cases of Trichuris trichiura infection worldwide (WHO 1990 and Bundy et al. 1992). On the other hand, WHO (1990) estimated that worldwide there were 1447 million and 1048 million cases of $A$. lumbricoides and T. trichiura infections, respectively. Children are more exposed to these soil-transmitted worms which are also associated with stunted growth (Kuntz 1960, Ahmed 1986, Ahmed 1989, Robert 1990, Rawsan 1993, Uddin and Khanum 2008 and Khanum et al. 2010) and impaired cognitive functions. The high prevalence rate of the parasites was correlated with poverty, poor environmental hygiene and impoverished health services (WHO 1990 and Uddin and Khanum 2006).

Dhaka, being the capital city of Bangladesh has more than 7 million people. A large part of this population resides in the slum areas with very poor living condition, where there is practically no provision for safe water supply and safe excreta disposal system. A number of studies has so far been conducted in slum areas and other parts of Dhaka city where the socio-economic condition is miserable. Low socio-economic condition, poor hygienic habits, lack of sanitary latrines and lack of health education have been found to be related to wider prevalence of different parasitic infections (Nuruzzaman and Huda 1976, Khanum et al. 1999 and Uddin and Khanum 2006). Children, the most vulnerable among all the members of the low-income group families are suffering from various diseases and malnutrition. The aim of the present study was to identify the prevalence of four important parasitic infections affecting staffs, students and teachers working in University of Dhaka and to understand their seasonal prevalence rates.

\section{Materials and Methods}

A total of 350 stool samples was collected, processed and prepared for both macroscopic and microscopic examinations to detect the parasitic infestation of the teachers, students and staffs who came as out-door patient in Dhaka University Medical Center. Fresh stool samples were collected and examined as quickly as possible. In case of delayed examination, formalin ( $10 \%$ solution) was used as preservative. The samples were primarily examined microscopically by direct smear technique and also by formal- ether concentration method (Cheesbrough 1987). A formatted questionnaire was used to record the observations and results of the examinations of the present study. At first the selected persons were explained about the nature of the study through direct interview with each. The demographic, socioeconomic and sanitation of the household were observed and all relevant information were recorded in predefined questionnaire. The patients were then provided with clean containers for stool collection and all collected stools were preserved with $10 \%$ formalin for further examination. 
In microscopic examination, saline preparation, iodine preparation and floating technique were followed (Cheesbrough 1987). The presence of ova / cysts of protozoan parasites and eggs of helminth parasites by microscopy was indicative for the presence of adult/mature stages of parasites in the patients.

During this study, a predefined questionnaire were used to collect information concerning the lifestyle, socio-economic status, knowledge level of the patients and personal hygienic practices followed by the individuals who were included in the study.

\section{Results and Discussion}

Out of 350, only $81(23.14 \%)$ were found as positive cases for helminth and protozoan infection among the Teacher, Students and Staffs at Dhaka University Medical Center during the study period. The comperative analysis indicates that protozoan infection was higher than helminth infection in studied population (Fig. 1).

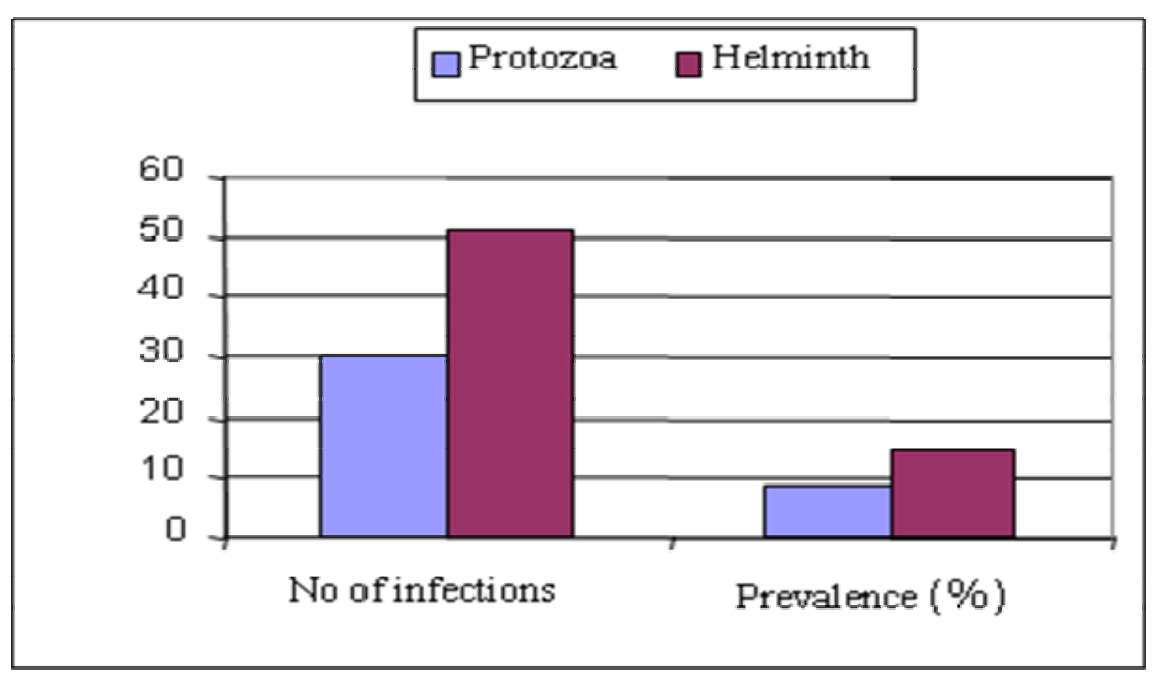

Fig 1. The prevalence of intestinal protozoan and helminth parasites.

Out of 350 only 17 were positive for Entamoeba histolytica and prevalence of infection was $4.86 \%$, 13 were positive for Giardia intestinalis and prevalence of infection was $3.714 \%$. The highest rate of infection $(11.142 \%$ ) was recorded with Ascaris lumbricoides where 39 cases were found to be positive. The lowest prevalence rate was recorded in Trichuris trichiura with only $3.43 \%$ positive cases (Table 1). 
Table 1. Overall prevalence of four different types of intestinal parasitic infection recorded during study period.

\begin{tabular}{lccc}
\hline Different parasites & $\begin{array}{c}\text { Total no. of sample } \\
\text { examined }\end{array}$ & $\begin{array}{c}\text { No. of infected } \\
\text { sample }\end{array}$ & $\begin{array}{c}\text { Prevalence (\%) } \\
(\mathrm{n}=350)\end{array}$ \\
\hline Entamoeba histolytica & 350 & 17 & 4.86 \\
Giardia intestinalis & 350 & 13 & 3.174 \\
Ascaris lumbricoides & 350 & 39 & 11.14 \\
Trichiuris trichiuria & 350 & 12 & 3.43 \\
\hline
\end{tabular}

The seasonal prevalence of different gastrointestinal parasites were investigated during the study period. Table 2 shows the prevalence rates of different parasites over three seasons namely winter, summer and rainy season. The sample size in different seasons were different and the difference in prevalence was recorded. Graphical representation of the same data ispresented in Fig. 2. The highest prevalence of E. histolytica was $7.33 \%$ and $5.33 \%$ of $G$. intestinalis in rainy season. The prevalence of $A$. lumbricoides was highest $(15.33 \%)$ in rainy season while that of . trichiura was $(4.69 \%)$ in winter (Table 2 and Fig. 3).

Table 2. Prevalence of different parasitic infection in three seasons.

\begin{tabular}{|c|c|c|c|c|c|c|c|c|c|}
\hline \multirow[t]{2}{*}{ Parasites } & \multicolumn{3}{|c|}{ Winter $(n=128)$} & \multicolumn{3}{|c|}{ Summer $(\mathrm{n}=72)$} & \multicolumn{3}{|c|}{ Rainy $(n=150)$} \\
\hline & $\begin{array}{c}\text { Total } \\
\text { sample } \\
\text { exam. }\end{array}$ & $\begin{array}{l}\text { No .of } \\
\text { infected } \\
\text { sample }\end{array}$ & $\begin{array}{l}\text { Prev. } \\
(\%)\end{array}$ & $\begin{array}{l}\text { Total } \\
\text { sample } \\
\text { exam. }\end{array}$ & $\begin{array}{l}\text { No. of } \\
\text { infected } \\
\text { sample }\end{array}$ & $\begin{array}{c}\text { Prev. } \\
(\%)\end{array}$ & $\begin{array}{c}\text { Total } \\
\text { sample } \\
\text { exam. }\end{array}$ & $\begin{array}{l}\text { No. of } \\
\text { infected } \\
\text { sample }\end{array}$ & $\begin{array}{c}\text { Prev. } \\
(\%)\end{array}$ \\
\hline E. histolytica & 128 & 4 & 3.13 & 72 & 2 & 2.78 & 150 & 11 & 7.33 \\
\hline G. intestinalis & 128 & 2 & 1.56 & 72 & 3 & 4.17 & 150 & 8 & 5.33 \\
\hline $\begin{array}{c}A . \\
\text { lumbricoides }\end{array}$ & 128 & 10 & 7.81 & 72 & 6 & 8.33 & 150 & 23 & 15.33 \\
\hline T. trichiura & 128 & 6 & 4.69 & 72 & 3 & 4.17 & 150 & 3 & 2 \\
\hline
\end{tabular}

\begin{tabular}{|c|c|c|c|}
\hline 20 & \\
15 & & \\
10 & & \\
\hline
\end{tabular}

Fig 2. Seasonal prevalence of different parasitic groups among the patients. 


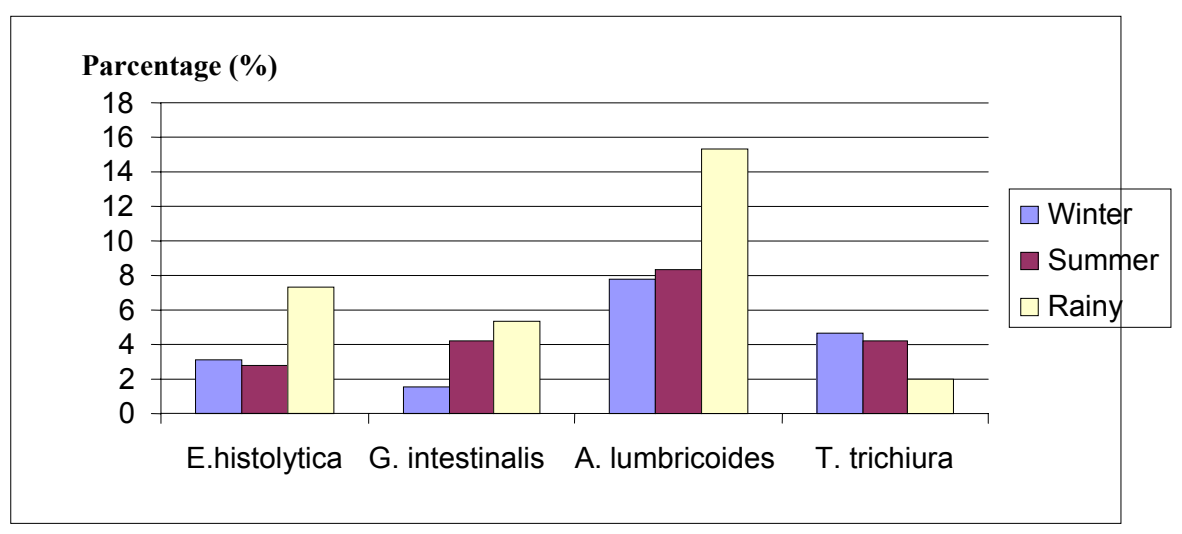

Fig 3. The prevalence of different parasitic infections in three seasons among the patients.

The monthly variation in prevalence of intestinal parasites was also analyzed during this study. The prevalence of infection was highest (66.67\%) in staffs group during October, 2009 and absence of positive cases was observed in teacher group in a number of months. However, the students group had the highest $(33.33 \%)$ prevalence rate recorded in September, 2009 and lowest (7.14\%) in March, 2010 of the following year (Table 3).

Table 3. Monthly variations in prevalence of the total gastrointestinal parasites among the patients.

\begin{tabular}{l|c|c|c|c|c|c|c|c|c}
\hline & \multicolumn{3}{|c|}{ Teacher } & \multicolumn{3}{c|}{ Student } & \multicolumn{3}{c}{ Staff } \\
\hline Months & $\begin{array}{c}\text { Total } \\
\text { sample }\end{array}$ & $\begin{array}{l}\text { No. of } \\
\text { infected }\end{array}$ & Prev. & $\begin{array}{c}\text { Total } \\
\text { sample }\end{array}$ & $\begin{array}{c}\text { No. of } \\
\text { infected }\end{array}$ & Prev. & $\begin{array}{c}\text { Total } \\
\text { sample }\end{array}$ & $\begin{array}{c}\text { No. of } \\
\text { infected }\end{array}$ & Prev. \\
\hline Jun '09 & 0 & 0 & 0 & 16 & 3 & 18.75 & 4 & 2 & 50 \\
July '09 & 3 & 1 & 33.33 & 23 & 6 & 26.08 & 19 & 7 & 36.84 \\
Aug '09 & 1 & 0 & 0 & 14 & 4 & 28.37 & 12 & 4 & 33.33 \\
Sep '09 & 2 & 0 & 0 & 27 & 9 & 33.33 & 5 & 1 & 20 \\
Oct '09 & 1 & 0 & 0 & 17 & 4 & 23.53 & 6 & 4 & 66.67 \\
Nov'09 & 2 & 1 & 50 & 12 & 2 & 16.67 & 15 & 3 & 20 \\
Dec '09 & 1 & 0 & 0 & 27 & 5 & 18.52 & 21 & 4 & 19.04 \\
Jan '10 & 0 & 0 & 0 & 21 & 3 & 14.29 & 4 & 0 & 0 \\
Feb '10 & 1 & 0 & 0 & 18 & 2 & 11.11 & 6 & 2 & 33.33 \\
Mar '10 & 0 & 0 & 0 & 14 & 1 & 7.14 & 5 & 2 & 40 \\
Apr '10 & 1 & 0 & 0 & 26 & 4 & 15.38 & 4 & 1 & 25 \\
May '10 & 1 & 0 & 0 & 10 & 3 & 30 & 11 & 3 & 27.27 \\
\hline
\end{tabular}


Helminthic infection specially soil transmitted nematodes are major health problem in this country. Many factors like, poor hygienic habits, poor standard of living, lack of health education, ignorance, poverty, poor socio-economic conditions are some of the many reasons behind high prevalence of parasitic infections in Bangladesh. Previous investigators have shown that intestinal parasite is a major health problem in our country and present data also support this statement.

During the present study, helminth infection was recorded to be higher compared to protozoan infection. This condition usually contributed by different level of environmental conditions which facilitate the transmission of the infective stages of the parasites. The seasonal prevalence was also informative to predict any possible rise of infection in any specific time of the year. This information will be useful for the medical facilities to be prepared with the necessary medications or planning the control of programs. Dhaka University is the largest University of the country and has high number of employees. Some of them live in good accommodations while many minimum-paid employees live in places near slums and they might not have access to clean drinking water or food. Therefore they are more prone to suffer from different intestinal parasites. This could be an important observation from the present study as it was found that staffs were having high infection rate over the years. The students' accommodation is also not very clean as suggested by the significant infection in different times of the year. The teachers are usually economically more stringer group out of the three groups in the study. They have comparatively better accommodation and therefore have less infection rate. One other issue could be that as the teachers have financial capacity, many of them may not be visiting the Dhaka University Medical Centre, rather visiting any good and modern hospitals located in Dhaka. Therefore these cases might not be available for analysis during this study.

The gastrointestinal parasitic infestation is a common public health problem in Bangladesh. Though clinically very small number of parasitic infestations are manifested, but this should be considered as the tip of iceberg. The prevalence of helminthiasis and protozoan infestivity is rampant in Bangladesh, which is leading to a cumulative economical loss of the country. The present study was carried out to find out the incidence of parasitic infections among the selected patients visiting the Dhaka University Medical centre. However this study is concentrated on only four parasites while one would expect many other protozoans and helminthes prevalent in the same community.

Further epidemiological study is essential to understand the distribution of different other parasites throughout the country and mass campaign is necessary to develop awareness among different communities to combat this infection which has considerable economic significance. 


\section{References}

Ahmed, A. U. 1986. A study on prevalence of Ascariasis and its nutritional status of under 5 children at Datta para, Tongi: DCM Dissertation, NIPSOM:16 pp.

Ahmed, M. M. 1989. A preliminary survey of parasitic infection and nutritional status among school children in Riyadh, Saudi Arabia. J. Egypt Sci. Parasitology. 19:101-105.

Bundy, D. A. A. Hall and G.F. Medly.1992. Evaluating measures to control. Intestinal parasitic infections. World Health Status-Q. 45:2-3.

Cheesbrough, M. 1987. Medical laboratory Mannual for Tropical countries, second edition. 1: Parasitology. Second Ed. Tropical Health Technology and Butterworth, London. 603 pp.

Chowdhury, A. U. 1986. Study on prevalence of ascariasis and its impact on nutritional status of under 5 children at dattapara,tongi DMC dissertation NIPSOM. 16pp.

Chowdhury, M. R. 1978. Intestinal parasitic infection in privileged class 01' Dhaka population. Bangladesh. Armed Forces Med .J. 4:5-12.

Islam, A.F.M., M. K. Sadeque, N. Biswas, A.U. Ahmed and G. Mahmood. 1975. Helminthiasis and anaemia in student of Dhaka university Bangladesh. Med Res Council bull. 11(1):40-45.

Khanum, H., S. Chawdhury and Z.J. Bhuiyan. 1999. Infestation of three intestinal worms in children of three selected areas, Bangladesh. Pakistan J. of Zool. 31(4): 391-396.

Khanum H., S. Chawdhury and A. Sen. 2001.Comparative efficacy of albendazole, mebendazole and neem leaf extract in the Treatment against human intestinal helminth. Trans. zool. Soc. East India. 5(1): 65-69.

Khanum, H., H. Uddin and M. Rahman, 2005. Hookworm infection and hygienic condition in the rural children of Bangladesh. Bangladesh J. Zool. 33 (1): 75-79.

Khanum, H., R. Islam and S. Parvin. 2010. Occurrences of egg and larvae of gastrointestinal nematodes in nails of street inhabitants in Dhaka city. J. Life Earth Sci. 5:75-79.

Kuntz, R. E. 1960. Intestinal protozoa and Helminths in School children in Dacca, East pakistan Armed, J. Trop. Med. Hyg. 9:168-173.

Muazzem, M.G. and M.T. Ali. 1968. Incidence of intestinal parasites among children of East Pakistan. Medicus. 25:21-215.

Muttalib. M.A. 1975. Intestinal parasites University of Dhaka students. J. Trop. Med Hyp. 78:1011.

Mutalib, M. A. , N. Islam and S. Islam. 1976. Prevalence of intestinal parasites in rural children of Bangladesh. Bangladesh Medical journal. 5(1): 9-27.

Nuruzzaman, M. and Q. Huda. 1976. Parasitic infestation in gastro intestinal tract disorder. $B$. M. J. 6(3): 67-72.

Robert, J. 1990. Association between intestinal parasites and nutritional status of 3-8 years old children in Norlhert Thailand, Trap. Geogr,. Med. 42(40):312.

Rowsan, A. 1993. Prevalence of intestinal helminths and its nutritional impact of under 5 years children in two urban dispensaries of Dhaka city, D.C.M. Dissertation, NIPSOM. 18 pp.

Saha, A. and A. B. Chowdhury. 1961. Helminthic infection in under five children in 
Rangpur and Dinajpur districts. Bang. Med. J. 16(2):7-11.

Stoll, B.J., R.I. Glass, M.I. Haq, J.E. Holt and H. Banu, 1982. Surveillance of patients attending at dierrhoeal disease hospital in Bangladesh. British Med. J. 285-1188.

Uddin, M. H. and H. Khanum. 2006. Hemoglobin level among adolescent girls and it's relation to intestinal parasites. Bangladesh J. Zool. 32(2): 183-188.

Uddin, H. M. and H. Khanum. 2008. Intestinal parasitic infestation and anaemic status among the adolescent boys in Bangladesh. Univ. j. zool. Rajshahi Univ. 27 :63-65.

W.H.O. 1990. List of estimated annual death ranked six parasites disease, World Health Organization, Geneva, Switzerland. 66pp.

(Received revised manuscript on 7 October 2013) 